\section{MS13 P01}

Anion binding using radicals as reporter groups Gareth O. Lloyd, Jonathan W., Department of Chemistry, Durham University. E-mail: g.o.lloyd@durham.ac.uk

\section{Keywords: Anion binding, Radicals, Urea groups}

Anion binding is recognized as one of the fastest growing disciplines of supramolecular and coordination chemistry. $[1,2]$ We report in this presentation the binding of a series of anions to a urea functionalized host.[3] The urea group is recognized for its ability to bind strongly to anions as it interacts with the anions through hydrogen bonds. The reporter group utilized in these experiments is a carbon radical, the trityl radical. A trityl radical is a central carbon atom that is the radical atom bound to three aromatic moieties. This remarkable stable group provides a spectroscopic handle for the sensing of the binding event. The aromatic moieties are functionalized with the urea groups. Single crystal x-ray analysis is used to correlate solution-based binding and investigate the interactions between the host (both hydrogen bonds and the binding effect on the radical) and the anionic guests.

[1] Martínez-Máñez, R.; Sancenón, F., Liles D.C., Chem. Rev., 2003, 103, 4419 .

[2] Beer, P. D.; Gale, P. A., Angew. Chem. Int. Ed., 2001, 40, 486. [3] Filby, M. H.; Steed, J. W., Coord. Chem. Rev., 2006, 250, 3200 .

\section{MS13 P02}

Design of new porous materials towards the storage and separation of gases Dinabandhu Das, Leonard J. Barbour, Department of Chemistry, University of Stellenbosch, South Africa. E-mail: dinu@sun.ac.za

\section{Keywords: porous material, hydrogen storage, metal organic structures}

The storage and separation of highly flammable gases such as hydrogen, acetylene and methane is a challenging task. In this context the use of metal-organic frameworks (MOFs) have drawn a great interest. Various MOFs are reported by several research groups [1]. We are interested in constructing three-dimensional diamondoid MOFs based on tetrahedral core. Here we report the synthesis and determination of the crystal structure of an organic ligand which is potentially useful to generate MOFs.

[1] Yaghi, O. M., O'Keeffe, M., Ockwig, N. W., Chae, H. K., Eddaoudi, M., Kim, J., Nature, 2003, 423, 705.

\section{MS13 P03}

Gas coordinates in porous supramolecular assemblies Jan-André Gertenbach, Liliana Dobrzańska, Tia Jacobs, Martin Bredenkamp and Leonard Barbour Chemistry Department, Stellenbosch University, Stellenbosch, Republic of South Africa. E-mail: jag@sun.ac.za

Keywords: gas-solid interactions, inclusion compounds, supramolecular

Supramolecular frameworks that are porous are known to be capable of accommodating gas in the pores within the lattice that constitutes the host system. The first such framework where gas coordinates were successfully located was reported more than 20 years ago[1] and numerous examples of this behaviour are now known.
Even so, the understanding of the nature of the interactions between host and guest is not yet as extensive and each novel system that is structurally solved provides new insights. Our work seeks to build on this understanding and some results are reported here

[1] Hirotsu, K., et al., J. Inclusion Phenom., 1984. 2, 215-222.

\section{MS13 P04}

New Class of Pillared Crystalline Compounds: Layered Rare-Earth Hydroxides. Enrique GutiérrezPuebla, Felipe Gándara, Angeles Monge, Natalia Snejko, Berta Gómez-Lor, Marta Iglesisas. Instituto de Ciencia de Materiales de Madrid. CSIC, Madrid, Spain.

E-mail: egutierrez@icmm.csic.es

Keywords: Layered materials, Hydrogen bonds, Rare earths

Compounds of the type presented herein, which are formed by pure cationic rare-earth hydroxide layers, represent a new generation of pillared materials, in which the properties of intercalation materials are combined with those of rare-earth elements. $\left[\mathrm{R}_{4}(\mathrm{OH})_{10}\left(\mathrm{H}_{2} \mathrm{O}\right)_{4}\right]_{n} \mathrm{~A}_{n}$ $(\mathrm{R}=$ rare-earth ions, $\mathrm{A}=$ intercalated organic anions, 2,6naphthalenedisulfonate $\left(\mathrm{NDS}^{2-}\right)$ or $2,6-$ anthraquinonedisulfonate $\left(\mathrm{AQDS}^{2-}\right)$ ) is the first family of layered rare-earth hydroxides (LRHs). In these LRHs, the positive charge of the inorganic layer is created only by trivalent rare-earth hydroxocations, which arises from the high and variable coordinative capability of the rare-earth centers and to the tendency of the hydroxide ion to form $\mu$ $\mathrm{n}$ connections in structures that contain these rare-earth centers. Rigid organic anions are hydrogen-bonded to the rare-earth hydroxide cationic layers and intercalated to neutralize the positive charge. These new materials contain a great number of active metal centers with the capability of varying the coordination number in catalytic processes, which confers to them great possibilities in the field of green chemistry. In fact, the performed tests in hydrodesulfurization (HDS), sulfide oxidation, and redox reactions reveal these new LRHs to be high-quality heterogeneous catalysts. Other interesting physical properties emerging from both the f-f interactions and those of intercalated organic anions are also to be expected.

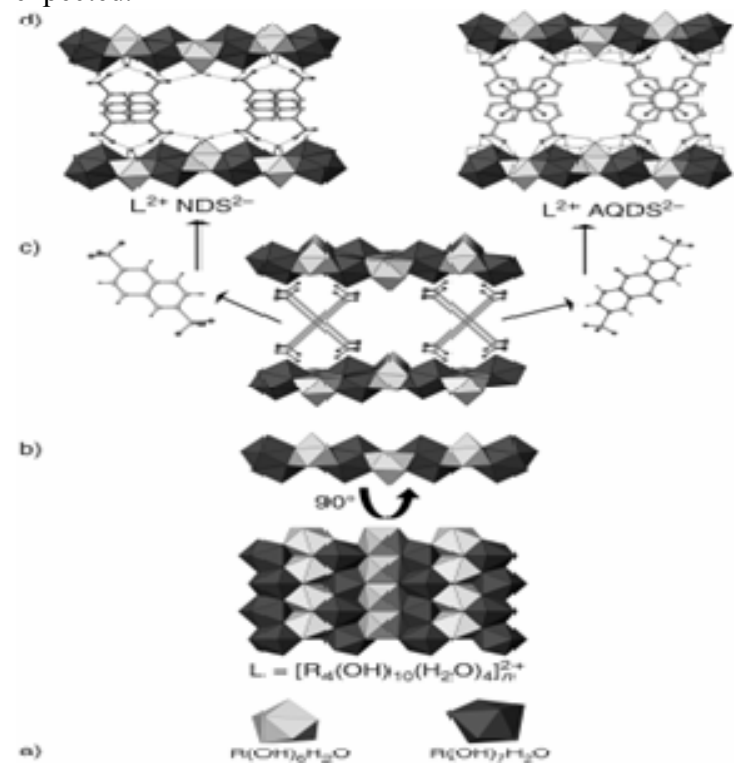

